\title{
Anisocytosis predicts postoperative renal replacement therapy in patients undergoing heart valve surgery
}

\author{
Piotr Duchnowski ${ }^{1}$, Tomasz Hryniewiecki ${ }^{1}$, Mariusz Kuśmierczyk ${ }^{2}$, Piotr Szymański ${ }^{1}$ \\ ${ }^{1}$ Department of Acquired Cardiac Defects, Institute of Cardiology, Warsaw, Poland \\ ${ }^{2}$ Department of Cardiosurgery and Transplantology, Institute of Cardiology, Warsaw, Poland
}

\begin{abstract}
Background: Acute kidney injury (AKI) is one of the serious postoperative complications in patients undergoing heart valve surgery. The aim of the present study was to identify selected biomarkers to predict AKI requiring renal replacement.

Methods: A prospective study was conducted on a group of 751 patients undergoing heart valve surgery. The data on risk factors, preoperative complete blood count, course of operations and postoperative period was assessed. The primary endpoint at the 30-day follow-up was postoperative AKI requiring renal replacement therapy. The secondary end-point was death from all causes in patients with postoperative AKI requiring renal replacement.

Results: The primary endpoint occurred in 46 patients. At multivariate analysis: age, red cell distribution width $(R D W)$ and $C$-reactive protein remained independent predictors of the primary endpoint. Hemoglobin and RDW were associated with an increased risk of death.

Conclusions: Elevated $R D W$ is associated with a higher risk of postoperative AKI and death in patients with AKI. (Cardiol J 2020; 27, 4: 362-367)

Key words: anisocytosis, red cell distribution width, valve surgery, acute kidney injury
\end{abstract}

\section{Introduction}

Acute kidney injury (AKI) in patients undergoing heart valve surgery is one of the serious postoperative complications associated with prolonged hospitalization, increased mortality as well as the occurrence of chronic kidney disease [1-3]. The diagnosis of AKI is based on two functional markers, an increase of serum creatinine and a reduction of urinary excretion. Predictors of perioperative AKI in patients undergoing heart surgery include preoperative creatinine level, endstage renal disease, 2-2 phenotype of haptoglobin, advanced age, diabetes mellitus, congestive heart failure, generalized atherosclerosis, cardiovascular collapse, nitric oxide, cyanotic heart disease, duration of surgery and elevated postoperative lactate level [4-9]. In patients with severe AKI, oliguria and fluid accumulation, renal replacement therapy is the basic method of treatment [10]. Hemodiafiltration seems to represent the gold standard in the field of replacement of renal function in patients undergoing heart valve surgery [11-13].

Red cell distribution width (RDW) is a parameter that reflects the variability of the size of red blood cells (anisocytosis). Elevated RDW is a result of erythrocytes production dysfunction related to a deficiency of folic acid, iron, vitamin B12 or ongoing inflammation as well as increased destruction of erythrocytes e.g. in the course of hemolysis. Previous studies have indicated the predictive ability of RDW in various cardiovascular disorders [14-24]. Identifying risk factors for developing AKI and aggressive early intervention is extremely important to optimize outcomes in patients with heart valve disease. Therefore, the aim of the present study

Address for correspondence: Piotr Duchnowski, MD, PhD, Department of Acquired Cardiac Defects, Institute of Cardiology, ul. Alpejska 42, 04-628 Warszawa, Poland, tel: +48 2234341 91, e-mail: duchnowski@vp.pl

Received: 9.11 .2018

Accepted: 7.02 .2019 
was to identify and evaluate selected biomarkers to predict AKI requiring renal replacement therapy in patients undergoing heart valve surgery.

\section{Methods}

A prospective study was conducted on a group of consecutive patients with hemodynamically significant valvular heart disease (aortic stenosis, aortic regurgitation, mitral stenosis and/or mitral regurgitation) that qualified for cardiac surgery and subsequently underwent elective replacement or repair of a valve/valves. The exclusion criteria were: patients under 18 years of age, a lack of consent to participate in the study, hemolytic disease, blood transfusion before surgery in the last 3 months, active neoplastic diseases, autoimmune diseases, chronic inflammatory bowel and active endocarditis. One day prior to surgery a blood sample for biomarkers was collected from each patient. Full blood counts were measured from $\mathrm{K}_{2}$ EDTA samples using a Sysmex K-4500 electronic counter. The glomerular filtration rate (GFR) was estimated based on a simplified MDRD pattern: GFR $\left(\mathrm{mL} / \mathrm{min} / 1.73 \mathrm{~m}^{2}\right)=186.3 \times$ [creatinine concentration $(\mathrm{mg} / \mathrm{dL})]-1.154 \times$ [age (years)] $-0.203 \times \mathrm{C}$, where $\mathrm{C}$ stood: for men -1 , for women -0.742 . Chronic renal failure was defined as chronic (lasting at least 3 months) impaired renal function, understood as a reduction in GFR $<60 \mathrm{~mL} / \mathrm{min} / 1.73 \mathrm{~m}^{2}$ and included the following stages of chronic kidney disease (CKD), stage 3 CKD (GFR 45-59 mL/min $/ 1.73 \mathrm{~m}^{2}$ ), stage $3 b$ CKD (GFR $30-44 \mathrm{~mL} / \mathrm{min} / 1.73 \mathrm{~m}^{2}$ ), stage 4 CKD (GFR $15-29 \mathrm{~mL} / \mathrm{min} / 1.73 \mathrm{~m}^{2}$ ) and stage $5 \mathrm{CKD}(\mathrm{GFR}$ $<15 \mathrm{~mL} / \mathrm{min} / 1.73 \mathrm{~m}^{2}$ ). AKI was diagnosed as an increase in serum creatinine ( $\mathrm{SCr}$ ) by at least 0.3 $\mathrm{mg} / \mathrm{dL}(26.5 \mu \mathrm{mol} / \mathrm{L})$ within $48 \mathrm{~h}$ or a urine volume of less than $0.5 \mathrm{~mL} / \mathrm{kg} / \mathrm{h}$ for $6 \mathrm{~h}$. The decision to start hemodiafiltration was made by the team of anesthesiologists responsible for the patient with the diagnosis of AKI and persisting high parameters of the kidneys (creatinine and/or urea) and anuria despite intensive conservative treatment. Continuous veno-venous hemodiafiltration was performed in all of the patients qualifying for renal replacement therapy. The primary end-point was perioperative AKI requiring renal replacement therapy. The secondary end-point was death from all causes in patients with perioperative renal replacement therapy. Patient follow-up was for 30 days or until death. The follow-up of discharged patients was conducted through direct observation during hospitalization and clinic visits for 30 days subsequent to surgery. The study was conducted at the Institute of Cardiology, Warsaw, Poland between January 12014 and September 302018. The protocol was approved by The Institutional Ethics Committee.

\section{Statistical analysis}

Statistical analysis was performed using the SAS version 9.2. Data are presented as the mean \pm standard deviation and frequency (percentage). The Shapiro-Wilk test of normality was used to test sample distribution. Intergroup comparisons were made using the Mann-Whitney U test, the Pearson's $\chi^{2}$ test or Student t-test. Delta 1 RDW value $(\triangle 1 \mathrm{RDW})$ defined as RDW measured $48 \mathrm{~h}$ after surgery minus preoperative RDW. Delta $2 \mathrm{RDW}$ value $(\triangle 2 \mathrm{RDW})$ defined as RDW measured $94 \mathrm{~h}$ after surgery minus preoperative RDW. Logistic regression was used to assess relationships between variables. The following covariates: age, aortic cross-clamp time, cardiopulmonary bypass time, preoperative atrial fibrillation, body mass index (BMI), GFR, chronic obstructive airways disease, coronary artery disease, current smoker, dyslipidemia, EuroSCORE II, hypertension, insulin dependent diabetes mellitus, left ventricular ejection fraction, New York Heart Association (NYHA) classes, peripheral atherosclerosis, previous myocardial infarction, pulmonary blood pressure, stroke history, total cholesterol, creatinine, high sensitivity troponin $\mathrm{T}, \mathrm{C}$-reactive protein (CRP), hematocrit, hemoglobin, mean corpuscular hemoglobin, mean corpuscular volume, platelets, preoperative RDW, RDW measured $48 \mathrm{~h}$ after surgery (RDW1), RDW measured $96 \mathrm{~h}$ after surgery (RDW2), $\Delta 1 \mathrm{RDW}$, $\triangle 2 \mathrm{RDW}$ and white blood cell count were investigated for association with endpoints in univariate analysis. Significant determinants $(p<0.05)$ identified from univariate analysis were subsequently entered into multivariate models. Predictive value of RDW was assessed by a comparison of the areas under the receiver operator characteristics of the respective curve. On the basis of the Youden index, a cut-off point was determined that met with the criterion of maximum sensitivity and specificity for perioperative renal replacement therapy.

\section{Results}

The study group included 751 consecutive patients who underwent replacement or repair of a valve/valves. The mean age was $63.5 \pm 13$ (Table 1). Two hundred twenty (29\%) patients had preoperative chronic renal failure (stage $3 \mathrm{a}$ 
Table 1. Baseline characteristics of the study population.

\begin{tabular}{|c|c|c|c|c|}
\hline Characteristics of patients $(n=751)$ & Values & $\begin{array}{c}\text { Values } \\
\text { with RRT }\end{array}$ & $\begin{array}{c}\text { Values } \\
\text { without RRT }\end{array}$ & $\mathbf{P}$ \\
\hline Age [years] & $63.5 \pm 13$ & $69 \pm 10$ & $61 \pm 13$ & 0.002 \\
\hline Male: men & $426(57 \%)$ & $22(47 \%)$ & $404(57 \%)$ & NS \\
\hline Body mass index $\left[\mathrm{kg} / \mathrm{m}^{2}\right]$ & $27 \pm 9$ & $26 \pm 7$ & $27 \pm 10$ & NS \\
\hline NYHA (classes) & $2.6 \pm 0.5$ & $2.8 \pm 0.8$ & $2.4 \pm 0.5$ & 0.004 \\
\hline LV ejection fraction [\%] & $56 \pm 12$ & $54 \pm 13$ & $58 \pm 10$ & NS \\
\hline Pulmonary blood pressure $[\mathrm{mmHg}]$ & $43 \pm 17$ & $55 \pm 19$ & $40 \pm 9$ & 0.005 \\
\hline EuroSCORE II [\%] & $3.55 \pm 3.4$ & $7 \pm 5$ & $3 \pm 2$ & 0.006 \\
\hline Atrial fibrillation & $318(42 \%)$ & $33(71 \%)$ & $285(40 \%)$ & 0.004 \\
\hline Chronic renal failure (GFR $<60 \mathrm{~mL} / \mathrm{min} / 1.73 \mathrm{~m}^{2}$ ) & $220(29 \%)$ & $25(54 \%)$ & $195(27 \%)$ & 0.03 \\
\hline Chronic obstructive airways disease & $42(6 \%)$ & $4(8 \%)$ & $38(5 \%)$ & NS \\
\hline Coronary artery disease & $185(24 \%)$ & $9(19 \%)$ & $176(25 \%)$ & NS \\
\hline Peripheral atherosclerosis & $55(7 \%)$ & $5(7 \%)$ & $38(6 \%)$ & NS \\
\hline Previous myocardial infarction & $79(10 \%)$ & $6(13 \%)$ & $73(10 \%)$ & NS \\
\hline Stroke history & $50(7 \%)$ & $1(2 \%)$ & $49(7 \%)$ & NS \\
\hline Hypertension & $468(62 \%)$ & $26(56 \%)$ & $442(62 \%)$ & NS \\
\hline Insulin dependent diabetes mellitus & $26(3 \%)$ & $1(2 \%)$ & $25(3 \%)$ & NS \\
\hline Current smoker & $145(19 \%)$ & $8(15 \%)$ & $137(29 \%)$ & NS \\
\hline Cholesterol (total) [mmol/L] & $4.7 \pm 0.9$ & $4.4 \pm 1.2$ & $4.8 \pm 0.9$ & 0.03 \\
\hline Hematocrit [\%] & $46 \pm 10$ & $37 \pm 13$ & $47 \pm 9$ & 0.001 \\
\hline Hemoglobin $[\mathrm{g} / \mathrm{dL}]$ & $13.7 \pm 1.5$ & $12.2 \pm 1.8$ & $14 \pm 1.4$ & 0.003 \\
\hline RDW [\%] & $13.8 \pm 1.1$ & $15.5 \pm 2$ & $13.5 \pm 1.0$ & $<0.001$ \\
\hline RDW1 [\%] & $14.2 \pm 1.3$ & $15.8 \pm 2.1$ & $14 \pm 1.4$ & 0.01 \\
\hline RDW2 [\%] & $14.4 \pm 1.4$ & $15.9 \pm 2.2$ & $14.1 \pm 1.3$ & 0.04 \\
\hline$\Delta 1 \mathrm{RDW}$ & $0.4 \pm 0.2$ & $0.3 \pm 0.1$ & $0.5 \pm 0.4$ & NS \\
\hline$\triangle 2 \mathrm{RDW}$ & $0.6 \pm 0.3$ & $0.4 \pm 0.2$ & $0.6 \pm 0.3$ & NS \\
\hline C-reactive protein [mmol/L] & $93 \pm 32$ & $136 \pm 48$ & $90 \pm 28$ & 0.002 \\
\hline $\mathrm{CRP}[\mathrm{mg} / \mathrm{dL}]$ & $0.44 \pm 0.35$ & $0.89 \pm 0.6$ & $0.34 \pm 0.3$ & 0.002 \\
\hline Hs-TnT [ng/L] & $36 \pm 28$ & $73 \pm 52$ & $22 \pm 17$ & 0.003 \\
\hline Platelets [1000/uL] & $192 \pm 60$ & $188 \pm 58$ & $195 \pm 62$ & NS \\
\hline Aortic cross-clamp time [min] & $91 \pm 39$ & $94 \pm 41$ & $89 \pm 30$ & NS \\
\hline Cardiopulmonary bypass time [min] & $115 \pm 45$ & $121 \pm 46$ & $112 \pm 42$ & 0.04 \\
\hline Hemodiafiltration time [days] & $3 \pm 2$ & & & \\
\hline \multicolumn{5}{|l|}{ Main procedures } \\
\hline AVR & $219(29 \%)$ & $15(32 \%)$ & $204(28 \%)$ & NS \\
\hline AVR + supracoronary ascending aortic replacement & $82(11 \%)$ & $3(7 \%)$ & $79(11 \%)$ & NS \\
\hline AVP & $4(0.5 \%)$ & & & \\
\hline Bentall procedure & $55(7 \%)$ & & & \\
\hline David procedure & $5(0.6 \%)$ & & & \\
\hline$A V R+M V R$ & $68(9 \%)$ & $9(19 \%)$ & $79(11 \%)$ & 0.4 \\
\hline AVR + MVP & $17(2 \%)$ & & & \\
\hline AVP + MVP & $7(1 \%)$ & & & \\
\hline MVP & $149(20 \%)$ & $9(20 \%)$ & $140(19 \%)$ & ns \\
\hline MVR & $145(19 \%)$ & $10(21 \%)$ & $135(19 \%)$ & ns \\
\hline \multicolumn{5}{|l|}{ Concomitant procedures } \\
\hline Coronary artery bypass grafting & $104(14 \%)$ & $14(30 \%)$ & $90(12 \%)$ & 0.4 \\
\hline
\end{tabular}

The values are represented by the mean and a measure of the variation of the internal standard deviation. AVR - aortic valve replacement; AVP - aortic valve plasty; GFR - glomerular filtration rate; Hs-TnT — high sensitivity troponin T; LV - left ventricle; MVR - mitral valve replacement; MVP — mitral valve plasty; NYHA - New York Heart Association; RDW - red cell distribution width (preoperative); RDW1 - red cell distribution width measured 48 hours after surgery; RDW2 - red cell distribution width measured $96 \mathrm{~h}$ after surgery; $\Delta 1 \mathrm{RDW}$ - defined as RDW measured $48 \mathrm{~h}$ after surgery - preoperative RDW; $\triangle 2 \mathrm{RDW}$ - defined as RDW measured $96 \mathrm{~h}$ after surgery - preoperative RDW; RRT - renal replacement therapy 
Table 2. Analysis of predictive factors for the occurrence of postoperative renal replacement therapy.

\begin{tabular}{|c|c|c|c|c|c|c|}
\hline \multirow[t]{2}{*}{ Variable } & \multicolumn{3}{|c|}{ Univariate analysis } & \multicolumn{3}{|c|}{ Multivariate analysis } \\
\hline & Odds ratio & $95 \% \mathrm{Cl}$ & $\mathbf{P}$ & Odds ratio & $95 \% \mathrm{Cl}$ & $\mathbf{P}$ \\
\hline Age [years] & 1.066 & $1.031-1.103$ & 0.002 & 1.082 & $1.019-1.162$ & 0.02 \\
\hline CBT [min] & 1.202 & $1.101-1.303$ & 0.04 & & & \\
\hline $\mathrm{CRP}[\mathrm{mg} / \mathrm{dL}]$ & 2.442 & $1.546-3.556$ & 0.002 & 2.386 & $1.416-3.268$ & 0.04 \\
\hline Creatinine [mmol/L] & 1.160 & $1.094-1.242$ & 0.001 & & & \\
\hline $\mathrm{GFR}\left[\mathrm{mL} / \mathrm{min} / 1.73 \mathrm{~m}^{2}\right]$ & 0.944 & $0.927-0.962$ & 0.004 & & & \\
\hline Hemoglobin [g/dL] & 0.595 & $0.491-0.721$ & 0.001 & & & \\
\hline LVEF [\%] & 0.966 & $0.944-0.988$ & 0.003 & & & \\
\hline RDW [\%] & 1.697 & $1.290-2.233$ & 0.0002 & 1.578 & $1.208-2.544$ & 0.003 \\
\hline RDW1 [\%] & 1.798 & $1.135-2.448$ & 0.009 & & & \\
\hline
\end{tabular}

CBT - cardiopulmonary bypass time; CRP - C-reactive protein; GFR - glomerular filtration rate; LVEF — left ventricular ejection fraction; RDW - red cell distribution width (preoperative); RDW1 - red cell distribution width measured $48 \mathrm{~h}$ after surgery

CKD -151 patients, stage $3 \mathrm{~b} C K D-52$ patients, stage $4 \mathrm{CKD}-17$ patients and stage $5 \mathrm{CKD}-$ 0 patients). All procedures were performed through a midline sternotomy incision under general anesthesia in normothermia. The mean preoperative RDW level was $13.8 \% \pm 1.1$. Table 1 shows characteristics of patients studied. Forty-six patients required renal replacement therapy (25 patients with preoperative chronic renal failure). The statistically significant predictors of postoperative renal replacement therapy at univariate and multivariate analysis are presented in Table 2. At multivariate analysis: age (odds ratio [OR] 1.082; 95\% confidence interval [CI] 1.019-1.162; $\mathrm{p}=0.02)$, RDW (OR 1.578; 95\% CI 1.208-2.544; $\mathrm{p}=0.003)$ and CRP (OR 2.386; 95\% CI 1.416$-3.268 ; \mathrm{p}=0.04$ ) remained independent predictors of the primary endpoint. The optimal cut-off point for postoperative renal replacement therapy was calculated at $>14.3 \%$ RDW (sensitivity $80 \%$, specificity $76 \%$ ). The area under receiver operator characteristic curve for postoperative AKI requiring renal replacement therapy for RDW is 0.804 (95\% CI 0.772-0.832) (Fig. 1). Twenty-eight patients with AKI requiring renal replacement therapy died in 30-day follow-up (15 patients with preoperative chronic renal failure). Cause of death in all patients was the increasing multi-organ failure. Statistically significant predictors of death from all causes in patients with postoperative renal replacement therapy at univariate and multivariate analysis are presented in Table 3. At multivariate analysis, hemoglobin (OR 1.015; 95\% CI 1.004-1.026; $\mathrm{p}=0.01$ ) and RDW (OR 1.288; 95\% CI 1.152-1.422; $\mathrm{p}=0.04$ ) remained predictors of mortality.

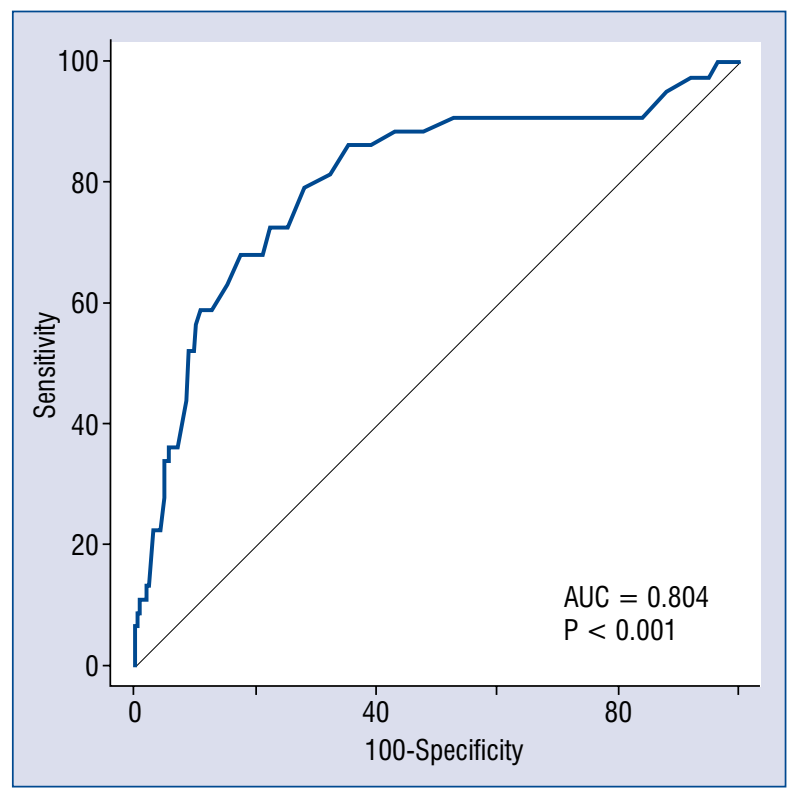

Figure 1. Area under receiver operating characteristic curve (AUC) of red cell distribution width for a renal replacement therapy following valve replacement/repair surgery.

\section{Discussion}

Acute kidney injury requiring renal replacement therapy is a common and significant complication after heart valve surgery. The present study revealed that this complication was seen in $6 \%$ of patients following heart valve surgery. The aim of this study was the evaluation and identification of predictors perioperative AKI requiring renal replacement therapy in the early postoperative 
Table 3. Analysis of predictive factors for the occurrence of death in patients with renal replacement therapy.

\begin{tabular}{lcccccccc}
\hline Variable & \multicolumn{3}{c}{ Univariate analysis } & & \multicolumn{3}{c}{ Multivariate analysis } \\
\cline { 2 - 3 } & Odds ratio & $95 \% \mathrm{Cl}$ & $\mathbf{P}$ & & Odds ratio & $95 \% \mathrm{Cl}$ & $\mathrm{P}$ \\
\hline Age [years] & 1.069 & $1.003-1.145$ & 0.04 & & & & \\
Hemoglobin [g/dL] & 0.614 & $0.410-0.907$ & 0.01 & & 1.015 & $1.004-1.026$ & 0.01 \\
RDW [\%] & 1.433 & $1.185-1.781$ & 0.02 & & 1.288 & $1.152-1.422$ & 0.04 \\
\hline
\end{tabular}

$\mathrm{Cl}$ - confidence interval; RDW - red cell distribution width

period in patients undergoing heart valve surgery. In the present work RDW remained an independent predictor of AKI requiring renal replacement therapy and death from all causes in patients with primary endpoint. RDW is an inexpensive, simple and widely accessible parameter designated for each patient during a standard blood test. Predictive ability of the RDW in various cardiovascular disorders have been reported in numerous publications. However, information regarding the usefulness of RDW in patients undergoing heart valve surgery is very limited [14, 17-27]. The predictive power of the RDW for perioperative stroke and multiple organ dysfunction syndrome was previously demonstrated [17, 24]. According to available research, there are no reports describing the usefulness of RDW in anticipation of the renal replacement therapy in an early postoperative period in patients undergoing valve surgery. Zou et al. [28] described that an elevated RDW might be an independent prognostic factor for the severity and poor prognosis of AKI in patients undergoing cardiac surgery. Moreover, available literature has shown that higher values of RDW are associated with worse prognosis in patients with AKI treated with continuous renal replacement therapy [29]. The pathophysiological mechanisms that explain the relationship between increased RDW values and a worse prognosis are not clear. According to current knowledge, elevated RDW is the cause of impaired microcirculation. The older erythrocytes gradually lose the ability to deform the cell membrane. This feature is very important during the squeezing of anucleate cells through the vessels of small diameter in organs such as the kidneys. The rigid and large erythrocytes observed in patients with elevated values, RDW cannot squeeze through the capillaries and thus impair blood flow through microcirculation leading to renal tissue ischemia [30]. On the other hand, some authors connect RDW with a patient's physiologic reserve - the ability of cells to defend against the strong stress of hypoxia [31]. The reserve is very important in such stressful situations such as heart valve surgery. Elevated RDW, meant to reflect a reduced physiological reserve, may explain the fact of a higher incidence of serious complications in the postoperative period, such as postoperative AKI.

\section{Conclusions}

Red cell distribution width is a parameter that reflects the variability of the size of red blood cells (anisocytosis). Elevated RDW is a result of erythrocytes production dysfunction related to a deficiency of folic acid, iron, vitamin B12 or ongoing inflammation as well as increased destruction of erythrocytes e.g. in the course of hemolysis. The results of this study indicate that the RDW is a useful parameter for estimating the risk of postoperative renal replacement therapy and renal replacement therapy-related mortality in patients undergoing heart valve surgery. This was a singlecenter study that included a limited number of participating patients. In future studies, enlarging the group may allow confirmation of the results obtained. Further studies are needed to clarify the pathomechanisms linking an increased risk of perioperative renal replacement therapy in patients with a higher RDW.

Funding: Statutory work at the Institute of Cardiology, no 1705.

\section{Conflict of interest: None declared}

\section{References}

1. Knight JB, Lebovitz EE, Gelzinis TA, et al. Preoperative risk factors for unexpected postoperative intensive care unit admission: A retrospective case analysis. Anaesth Crit Care Pain Med. 2018; 37(6): 571-575, doi: 10.1016/j.accpm.2018.02.002, indexed in Pubmed: 29455034. 
2. Tóth R, Breuer T, Cserép Z, et al. Acute kidney injury is associated with higher morbidity and resource utilization in pediatric patients undergoing heart surgery. Ann Thorac Surg. 2012; 93(6): 1984-1990, doi: 10.1016/j.athoracsur.2011.10.046, indexed in Pubmed: 22226235.

3. Lopez-Delgado JC, Esteve F, Torrado H, et al. Influence of acute kidney injury on short- and long-term outcomes in patients undergoing cardiac surgery: risk factors and prognostic value of a modified RIFLE classification. Crit Care. 2013; 17(6): R293, doi: 10.1186/cc13159, indexed in Pubmed: 24330769.

4. Liu Y, Zhang H, Liu Y, et al. Risk factors and short-term prognosis of preoperative renal insufficiency in infective endocarditis. J Thorac Dis. 2018; 10(6): 3679-3688, doi: 10.21037/ jtd.2018.06.11, indexed in Pubmed: 30069366.

5. Dhoble A, Zhao Y, Vejpongsa P, et al. National 10-year trends and outcomes of isolated and concomitant tricuspid valve surgery. J Cardiovasc Surg (Torino). 2019; 60(1): 119-127, doi: 10.23736/ S0021-9509.18.10468-X, indexed in Pubmed: 29969002.

6. Lei C, Berra L, Rezoagli E, et al. Nitric oxide decreases acute kidney injury and stage 3 chronic kidney disease after cardiac surgery. Am J Respir Crit Care Med. 2018; 198(10): 1279-1287, doi: 10.1164/rccm.201710-2150OC, indexed in Pubmed: 29932345.

7. Amini S, Abbaspour H, Morovatdar N, et al. Risk factors and outcome of acute kidney injury after congenital heart surgery: a prospective observational study. Indian J Crit Care Med. 2017; 21(12): 847-851, doi: 10.4103/ijccm.IJCCM_459_16, indexed in Pubmed: 29307966.

8. Feng C, Naik BI, Xin W, et al. Haptoglobin 2-2 phenotype is associated with increased acute kidney injury after elective cardiac surgery in patients with diabetes mellitus. J Am Heart Assoc. 2017; 6(10), doi: 10.1161/JAHA.117.006565, indexed in Pubmed: 28982674.

9. Olivero JJ, Olivero JJ, Nguyen PT, et al. Acute kidney injury after cardiovascular surgery: an overview. Methodist Debakey Cardiovasc J. 2012; 8(3): 31-36, indexed in Pubmed: 23227284.

10. Romagnoli S, Ricci Z, Ronco C. Perioperative acute kidney injury: prevention, early recognition, and supportive measures. Nephron. 2018; 140(2): 105-110, doi: 10.1159/000490500, indexed in Pubmed: 29945154.

11. Ronco C. Hemodiafiltration: technical and clinical issues. Blood Purification. 2015; 40(1): 2-11, doi: 10.1159/000437403.

12. den Hoedt CH, Bots ML, Grooteman MPC, et al. CONTRAST Investigators. Online hemodiafiltration reduces systemic inflammation compared to low-flux hemodialysis. Kidney Int. 2014; 86(2): 423-432, doi: 10.1038/ki.2014.9, indexed in Pubmed: 24552852.

13. Eremenko AA, Pavlov MV, Kolpakov PE, et al. [The influence of continuous veno-venous haemodiafiltration start time on multiple organ dysfunction syndrome treatment results in cardiac surgery patients]. Anesteziol Reanimatol. 2013(2): 63-66, indexed in Pubmed: 24000655.

14. Duchnowski P, Hryniewiecki T, Stokłosa P, et al. Number of erythrocytes as a prognostic marker in patients undergoing heart valve surgery. Kardiol Pol. 2018; 76(4): 791-793, doi: 10.5603/ KP.2018.0076, indexed in Pubmed: 29652422.

15. Aslan D, Gümrük F, Gürgey A, et al. Importance of RDW value in differential diagnosis of hypochrome anemias. Am J Hematol. 2002; 69(1): 31-33, indexed in Pubmed: 11835328.

16. Montagnana M, Cervellin G, Meschi T, et al. The role of red blood cell distribution width in cardiovascular and thrombotic disorders. Clin Chem Lab Med. 2011; 50: 635-41.
17. Duchnowski P, Hryniewiecki T, Kusmierczyk M, et al. Red cell distribution width is a prognostic marker of perioperative stroke in patients undergoing cardiac valve surgery. Interact Cardiovasc Thorac Surg. 2017; 25(6): 925-929, doi: 10.1093/icvts/ivx216, indexed in Pubmed: 29049563.

18. Montagnana M, Cervellin G, Meschi T, et al. The role of red blood cell distribution width in cardiovascular and thrombotic disorders. Clin Chem Lab Med. 2011; 50: 635-641.

19. Salvagno GL, Sanchis-Gomar F, Picanza A, et al. Red blood cell distribution width: A simple parameter with multiple clinical applications. Crit Rev Clin Lab Sci. 2015; 52(2): 86-105, doi: 10.31 09/10408363.2014.992064, indexed in Pubmed: 25535770.

20. Duchnowski P, Hryniewiecki T, Stokłosa P, et al. Red Cell Distribution Width as a Prognostic Marker in Patients Undergoing Valve Surgery. J Heart Valve Dis. 2017; 26: 714-720.

21. Tonelli M, Sacks F, Arnold M, et al. Relation between red blood cell distribution width and cardiovascular event rate in people with coronary disease. Circulation. 2008; 117: 163-168.

22. Duchnowski P, Hryniewiecki T, Kuśmierczyk M, et al. The usefulness of selected biomarkers in aortic regurgitation. Cardiol J. 2019; 26(5): 477-482, doi: 10.5603/CJ.a2018.0108, indexed in Pubmed: 30234893.

23. Balta S, Demirkol S, Aydogan M, et al. Red cell distribution width is a predictor of mortality in patients undergoing coronary artery bypass surgery. Eur J Cardiothorac Surg. 2013; 44(2): 396-397, doi: 10.1093/ejcts/ezt073, indexed in Pubmed: 23428577.

24. Duchnowski P, Hryniewiecki T, Kuśmierczyk M, et al. Red cell distribution width as a predictor of multiple organ dysfunction syndrome in patients undergoing heart valve surgery. Biol Open. 2018; 7(10), doi: 10.1242/bio.036251, indexed in Pubmed: 30127093.

25. Magri CJ, Chieffo A, Latib A, et al. Red blood cell distribution width predicts one-year mortality following transcatheter aortic valve implantation. Int J Cardiol. 2014; 172(2): 456-457, doi: 10.1016/j.ijcard.2013.12.216, indexed in Pubmed: 24529824.

26. Aung N, Dworakowski R, Byrne J, et al. Progressive rise in red cell distribution width is associated with poor outcome after transcatheter aortic valve implantation. Heart. 2013; 99: 1261-1266 .

27. Duchnowski P, Hryniewiecki T, Koźma M, et al. High-sensitivity troponin $\mathrm{T}$ is a prognostic marker of hemodynamic instability in patients undergoing valve surgery. Biomark Med. 2018; 12(12): 1303-1309, doi: 10.2217/bmm-2018-0186, indexed in Pubmed: 30520660.

28. Zou Z, Zhuang Y, Liu L, et al. Role of elevated red cell distribution width on acute kidney injury patients after cardiac surgery. BMC Cardiovasc Disord. 2018; 18: 166.

29. Vashistha T, Streja E, Molnar MZ, et al. Red cell distribution width and mortality in hemodialysis patients. Am J Kidney Dis. 2016; 68(1): 110-121, doi: 10.1053/j.ajkd.2015.11.020, indexed in Pubmed: 26786297.

30. Patel KV, Mohanty JG, Kanapuru B, et al. Association of the red cell distribution width with red blood cell deformability. Adv Exp Med Biol. 2013; 765: 211-216.

31. Friedman JS, Lopez MF, Fleming MD, et al. SOD2-deficiency anemia: protein oxidation and altered protein expression reveal targets of damage, stress response, and antioxidant responsiveness. Blood. 2004; 104(8): 2565-2573, doi: 10.1182/ blood-2003-11-3858, indexed in Pubmed: 15205258. 